TITLE:

\title{
ON THE MECHANISM OF THE ACTIVITY RHYTHM OF THE SEA- PEN, CAVERNULARIA OBESA VALENCIENNES
}

\author{
AUTHOR(S): \\ Imafuku, Michio
}

\section{CITATION:}

Imafuku, Michio. ON THE MECHANISM OF THE ACTIVITY RHYTHM OF THE SEA-PEN, CAVERNULARIA OBESA VALENCIENNES. PUBLICATIONS OF THE SETO MARINE BIOLOGICAL LABORATORY 1976, 23(1-2): 1-17

ISSUE DATE:

1976-07-31

URL:

http://hdl.handle.net/2433/175927

RIGHT: 


\title{
ON THE MECHANISM OF THE ACTIVITY RHYTHM OF THE SEA-PEN, CAVERNULARIA OBESA VALENGIENNES ${ }^{1,2)}$
}

\author{
MichIO IMAFUKU \\ Department of Zoology, Faculty of Science, Kyoto University
}

With Text-figures $1-5$

\begin{abstract}
Efforts have been paid in the present experiments to clarify the mechanism of the expansion-contraction rhythm of the sea-pen. Results are summarized as follows: (1) The hydrogen ion concentration of the body fluid at the beginning of expansion was slightly lower at higher temperatures in the regular rhythm as well as in the case of omission of an expansion. (2) Injection of alkalized, acidified or natural sea water or saline solution induced the contracted colony to expand to a certain extent. (3) Injection of alkalized sea water did not make the expanded colony contract. (4) The expansioncontraction rhythm was affected by both the injection of alkalized sea water and the mechanical stimulation. As far as the results obtained are concerned, it is concluded that the rhythmic behavior of the sea-pen is under the control of a time-keeping mechanism independent of the rhythmic behavior itself, and that the mechanism is susceptible in this sea-pen to influences from the inside and outside.
\end{abstract}

\section{Introduction}

The physiological mechanism of the circadian rhythm is not yet clarified, though efforts have been made by many investigators, especially since 1960. In the present circumstances, it is generally suspected that there might be something independent of rhythmic phenomena but controlling them. Such a mechanism underlying the rhythmic phenomena such as the locomotory activity in rats (Rawson, 1960), mating reactivity in Paramecium (Imafuku, 1972), sporulation in Oedogonium (Bühnemann, 1955) and so on, was called the "clock" (Bünning, 1973, Sweeney, 1969). In all these experiments, rhythmic phenomena were suppressed by chemical or other treatments but recovered without any phase-shift when the effect of treatments was diminished or wholly removed; this suggested some time-keeping mechanism maintaining its running under the effect of treatments.

On the other hand, a different idea was presented as to the expansion-contraction rhythm of the sea-pen, Cavernularia obesa Valenciennes, in which the rhythmic phenomenon itself was involved in the time-keeping mechanism demanding no underly-

1) Contributions from the Seto Marine Biological Laboratory, No. 611.

2) Part of a dissertation submitted to the Kyoto University in partial fulfillment of the requirements for the degree of Ph. D. in Science.

Publ. Seto Mar. Biol. Lab., XXIII (1/2), 1-17, 1976.

(Article 1) 
ing clock (Mori, 1947), as this sea-pen was expanded by the increase of hydrogen ion concentration of the body fluid due to the accumulation of metabolites during the contracted state, but contracted by the decrease of hydrogen ion concentration due to the excretion of accumulated metabolites in the expanded state.

The present author has pursued the mechanism of the expansion-contraction rhythm of this sea-pen from the view point of the latter working hypothesis. A part of the work was published in 1973, the results being summarized in the following four points: (1) A phase-shift was induced by the injection of acidified sea water. (2) The temperature coefficients of oxygen-consumption and the period of rhythm were 2.53 and 1.00 respectively in the range from 20 to $30^{\circ} \mathrm{C}$. (3) The period of rhythm was temporarily changed by a sudden change in a certain temperature range. (4) Rarely, an active expanded state was omitted without inducing any subsequent phase-shift. The first point (1) supports the working hypothesis mentioned above but the last (4) is seemingly left unexplained by this hypothesis.

The present paper deals with the results of further experiments with this seapen on the mechanism of the expansion-contraction rhythm, made after 1972 at the Seto Marine Biological Laboratory. Materials used were collected from Hatakejima Island and near the laboratory. Methods were the same as reported in the previous paper (Imafuku, 1973).

\section{Results}

\section{Hydrogen Ion Concentration of the Body Fluid at Different Temperatures:}

If the rhythmic activity is based on the metabolism affected generally by temperature, the period of rhythm will be shortened at higher temperatures but lengthened lower temperatures. However, the temperature coefficient of the period was calculated to be 1.00 from 20 to $30^{\circ} \mathrm{C}$, although the metabolism represented by oxygen-consumption was greatly affected by temperature in the same temperature range. Then it is necessary to examine whether or not the $\mathrm{pH}$ at the beginning of expansion is variable with temperature.

Several colonies ( $\mathrm{Pl}, \mathrm{P} 2, \mathrm{P} 3, \mathrm{P} 5, \mathrm{P} 6, \mathrm{P} 7$, weighing 8 to $29 \mathrm{~g}$ ) were kept in the aquarium more than one week at $25-27^{\circ} \mathrm{C}$ and $14-16^{\circ} \mathrm{C}$ respectively under the condition of a light-dark cycle with the light phase from 20:00 to 8:00. The colonies expressing a regular expansion-contraction rhythm in the aquarium and just expanding in the early dark phase were taken out and their body fluid was squeezed out by pressing respective colonies with hands after their surface was wiped with a towel. As far as they showed the expansion-contraction rhythm regularly related with the light-dark cycle, the same colonies were repeatedly used to obtain samples of the body fluid. The $\mathrm{pH}$ of body fluid sampled was measured by the $\mathrm{pH}$ meter, Hitachi-Horiba M-5, or by colorimetry of hydrogen ion concentration using phenol red as an indicator.

The results are shown in Table 1. The $\mathrm{pH}$ of the body fluid was 7.2-7.4 at higher temperatures of $25-27^{\circ} \mathrm{C}$, while it was $7.3-7.6$ at lower temperatures of $14-16^{\circ} \mathrm{C}$. 
Mean and standard deviations were calculated to be $7.30 \pm 0.07$ at higher temperatures and $7.44 \pm 0.10$ at lower temperatures. Thus, the $\mathrm{pH}$ of the body fluid was slightly lower at higher temperatures, but not so greatly affected as expected by the temperature-coefficient calculated from the oxygen-consumption (see Discussion).

Table 1. The $\mathrm{pH}$ of the body fluid of colonies kept at temperature $25-27^{\circ} \mathrm{C}$ and 14 $16^{\circ} \mathrm{C}$, measured in the expanding stage in the early part of the dark phase of light-dark cycle with the light phase from 20:00 to 8:00. Date, time, temperature and length of colony as well as volume and $\mathrm{pH}$ of the body fluid at measurements are given. The mean and standard deviation of $\mathrm{pH}$ of the body fluid are shown at the bottom of higher and lower temperatures.

\begin{tabular}{|c|c|c|c|c|c|c|c|}
\hline & \multirow{2}{*}{$\begin{array}{c}\text { Colony } \\
(\mathrm{g})\end{array}$} & \multirow{2}{*}{ Date } & \multirow{2}{*}{ Time } & \multirow{2}{*}{$\begin{array}{c}\text { Temperature } \\
\left({ }^{\circ} \mathrm{C}\right)\end{array}$} & \multirow{2}{*}{$\begin{array}{l}\text { Colony length } \\
(\mathrm{cm})\end{array}$} & \multicolumn{2}{|c|}{ Body fluid } \\
\hline & & & & & & Vol. $(\mathrm{m} l)$ & $\mathrm{pH}$ \\
\hline & $\mathrm{P} 2(18)$ & Sep. 28 & $9: 20$ & 26.8 & 10 & 19 & 7.4 \\
\hline Higher & P1 (26) & Sep. 28 & $9: 35$ & 26.8 & 15 & 44 & 7.3 \\
\hline \multirow[t]{4}{*}{ Temperatures } & P3 (8) & Oct. 4 & $9: 00$ & 25.6 & 7 & 10 & 7.2 \\
\hline & $\mathrm{P} 2$ (18) & Oct. 4 & $9: 00$ & 25.6 & 12 & 30 & 7.3 \\
\hline & \multicolumn{5}{|c|}{ range $25-27$} & \multicolumn{2}{|r|}{$7.30 \pm 0.07$} \\
\hline & P5 (29) & Sep. 28 & $9: 00$ & 15.1 & 10 & 51 & 7.4 \\
\hline Lower & P6 (26) & Oct. 4 & $9: 00$ & 15.1 & 20 & 74 & 7.4 \\
\hline \multirow[t]{4}{*}{ Temperatures } & P6 (26) & Nov. 2 & $10: 30$ & 14.8 & 10 & 30 & 7.5 \\
\hline & P5 (29) & Nov. 2 & $12: 30$ & 14.8 & 10 & 50 & 7.3 \\
\hline & P7 (26) & Nov. 2 & $12: 30$ & 14.8 & 5 & 15 & 7.6 \\
\hline & \multicolumn{5}{|c|}{ range $14-16$} & \multicolumn{2}{|r|}{$7.44 \pm 0.10$} \\
\hline
\end{tabular}

Hydrogen Ion Concentration of the Body Fluid of the Colony That Omitted an Active Expanded Phase:

Occasionally an active expanded phase may be latent in the course of regular expansion-contraction rhythm of the sea-pen. Such a phenomenon was reported in the previous paper (1973) in the colonies kept under the condition of the lightdark cycle as well as the constant condition, and also observed in the present study as seen in Fig. 4 (colony 2A November 12, 20 and 23). This phenomenon is one of the reasons why questions are put to the working hypothesis that the expansioncontraction rhythm of the sea-pen is induced by the excretion and accumulation of hydrogen ions. According to this hypothesis, a regular rhythm is explained in a way that metabolites gradually accumulated during the contracted state to a certain amount in a relatively fixed time induce the contracted animal to expand. Therefore, the omission of an active expanded phase or a prolonged contracted state brought about by it seemingly can hardly be explained by the working hypothesis. One of the possible explanations of this phenomenon might be given by measurement of the $\mathrm{pH}$ of the body fluid in the colony just omitted an active expanded phase.

A colony (Colony $\mathrm{M}$, weighing $18 \mathrm{~g}$ ) skipped an active expanded phase in a 
dark phase of light-dark cycle was taken out at the beginning of expansion in the next dark phase to examine the $\mathrm{pH}$ of its body fluid in the same way as in the previous experiment. The $\mathrm{pH}$ of this colony was 7.4 at the temperature of $28.5^{\circ} \mathrm{C}$, which was not different from that of the same colony presented later nearly the same $\mathrm{pH}$ value (7.3) at the beginning of an expanding phase in the following regular rhythm (Fig. 1).

Thus, the $\mathrm{pH}$ in the expanding phase seemed constant regardless of the omission of expansion. This result may be explained either by a sudden decrease by some unknown cause of the accumulation rate of hydrogen ions at the time of omission or by a supposition that the body fluid is provided with an ability to maintain the hydrogen ion concentration within a certain range by buffer action and therefore the expansion is triggered rather independently of the hydrogen ion concentration. The latter, suggesting a mechanism other than the change in hydrogen ion concentration, may be supported by the following experiment.

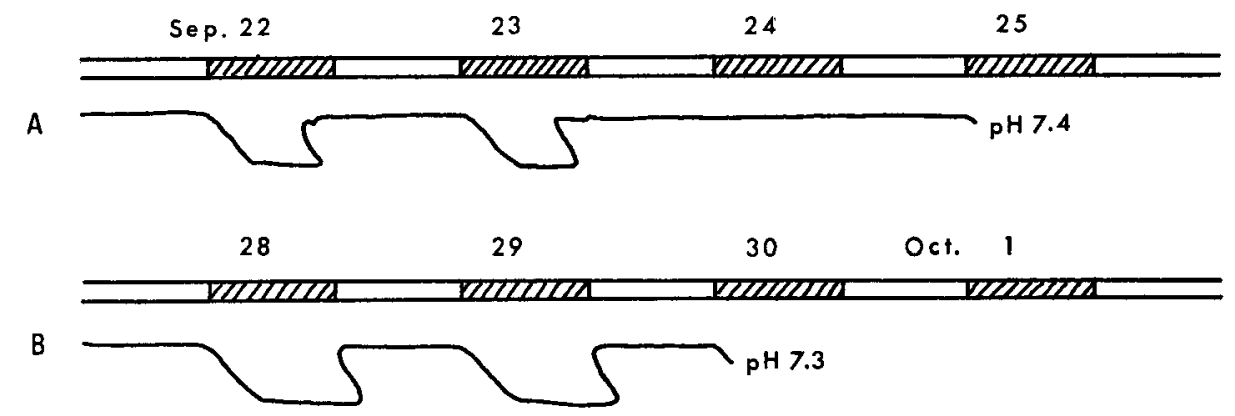

Fig. 1. The $\mathrm{pH}$ of the body fluid at the beginning of expansion, after skipping an expansion (A) and in the regular rhythm (B). The body fluid of the colony (Colony M, body weight $18 \mathrm{~g}$ ) kept in the light-dark cycle with the light phase from 20:00 to 8:00 and at the temperature $28.5^{\circ} \mathrm{C}$ was sampled at $9: 25$ on September $25(\mathrm{~A}, 14 \mathrm{ml})$, when the colony was expanded above the sand floor by $4 \mathrm{~cm}$, and again at $9: 15$ on September $30(\mathrm{~B}, 28 \mathrm{ml})$, when the colony was expanded above the sand floor by $7 \mathrm{~cm}$.

\section{Effects of Injection of Alkalized, Acidified, or Natural Sea Water to Contracted Animals:}

The working hypothesis is based significantly on a fact that the injection of acidified sea water induced the contracted colony to expand (Mori, 1945). Then, an experiment from the quite opposite view point, namely to see whether or not the injection of alkalized sea water induces the expansion of the contracted colony, must be very significant, too, to examine the validity of the working hypothesis. Thus, the experiments designed as follows were repeated three times.

The Frst Experiment (December 11, 1972 to April 18, 1973)

Ten colonies from 32 to $58 \mathrm{~g}$ in wet weight, which had been kept in glass cylinders under the condition of $12-\mathrm{h}$ light and $12-\mathrm{h}$ darkness, were injected with sea water alkalized by addition of sodium hydroxide or acidified by aeration with carbon dioxide or by addition of hydrochloric acid, or with natural sea water. The same colony was tested with various sea water many times. Treated or natural sea water of 
the volume 0.1 to $0.3 \mathrm{~m} l$ per gram of test animal was injected from the top of the contracted colony 2 to 4 hours after the beginning of the light phase of light-dark cycle. The light intensity in the light phase was 330 lux at the surface of sand floor in cylinders, and the dark phase was constantly under the dim light of about 1 lux. The temperature of running sea water, being heated in the coldest season,

Table 2. Effects of injection of alkalized, acidified and natural sea water (A and B) or saline solution (C). Injection was made 2 to 4 hours after the onset of the light phase or at dawn, to colonies kept in cylinders under the artificial light-dark cycle ( $\mathrm{A}$ and $\mathrm{C}$ ) or in the aquarium under the natural daylight (B). Sea water (S. W.) or saline solution $(\mathrm{NaCl}$ ) was alkalized by sodium hydroxide $(\mathrm{NaOH})$, acidified by carbon dioxide $\left(\mathrm{CO}_{2}\right)$ or hydrochloric acid $(\mathrm{HCl})$, or alkalized by liquid ammonia after once acidified by carbon dioxide ( $\mathrm{CO}_{2}+$ $\mathrm{NH}_{3}$ ). Positive $(+)$ shows that the contracted colony was expanded by injection more than half as long as in the usual expanded state. The numbers in parentheses just below the name of colony are weights in gram of colonies in the contracted state.

\begin{tabular}{|c|c|c|c|c|c|c|c|c|c|c|c|}
\hline & \multirow{2}{*}{ Date } & \multirow[b]{2}{*}{$\begin{array}{c}\text { Temp. } \\
\left({ }^{\circ} \mathrm{C}\right)\end{array}$} & \multicolumn{3}{|c|}{ Solutions Injected } & \multirow[b]{2}{*}{$\begin{array}{r}5 \mathrm{~A} \\
(37)\end{array}$} & \multirow[b]{2}{*}{$\begin{array}{r}2 \mathrm{~A} \\
(53)\end{array}$} & \multirow[b]{2}{*}{$\begin{array}{r}6 \mathrm{~A} \\
(38)\end{array}$} & \multirow[b]{2}{*}{$\begin{array}{r}50 \\
(58)\end{array}$} & \multirow[b]{2}{*}{$\begin{array}{r}\text { E1 } \\
(47)\end{array}$} & \multirow[b]{2}{*}{$\begin{array}{r}\mathrm{E} 2 \\
(35)\end{array}$} \\
\hline & & & Solute & $\mathrm{pH}$ & $\begin{array}{l}\text { Vol. } \\
(\mathrm{m} l / \mathrm{g})\end{array}$ & & & & & & \\
\hline \multirow{15}{*}{ ヶ } & \multirow[t]{2}{*}{ '72 Dec. } & 1115.1 & $\mathrm{NaOH}$ & 9.36 & 0.1 & - & - & - & - & - & \\
\hline & & $12 \quad 15-16$ & $\mathrm{NaOH}$ & 10.70 & 0.1 & - & - & & + & - & \\
\hline & \multirow[t]{3}{*}{ '73 Jan. } & 1620.0 & $\mathrm{NaOH}$ & 10.32 & 0.1 & - & - & & & & \\
\hline & & $19 \quad 20-22$ & $\mathrm{NaOH}$ & 10.28 & 0.1 & - & + & - & - & & - \\
\hline & & $23 \quad 21-22$ & $\mathrm{NaOH}$ & 9.20 & 0.1 & - & - & - & - & & \\
\hline & \multirow[t]{3}{*}{ Feb. } & 719.0 & $\mathrm{CO}_{2}$ & 4.42 & 0.1 & - & + & + & & & \\
\hline & & 1218.0 & $\mathrm{CO}_{2}$ & 4.66 & 0.3 & - & - & & - & & \\
\hline & & $14 \quad 20.5$ & $\mathrm{CO}_{2}$ & 4.60 & 0.3 & - & - & + & - & + & \\
\hline & Date & Temp. & Solute & $\mathrm{pH}$ & Vol. & $\begin{array}{r}\text { G1 } \\
(44) \\
\end{array}$ & $\begin{array}{r}\text { G2 } \\
(57) \\
\end{array}$ & $\begin{array}{r}\text { G4 } \\
(48) \\
\end{array}$ & $\begin{array}{r}\text { G5 } \\
(32) \\
\end{array}$ & $\begin{array}{r}\text { E1 } \\
(47) \\
\end{array}$ & $\begin{array}{r}\mathrm{E} 2 \\
(35) \\
\end{array}$ \\
\hline & \multicolumn{2}{|c|}{ '73 Mar. 218.0} & $\mathrm{CO}_{2}$ & 4.75 & 0.1 & - & - & + & & & - \\
\hline & \multicolumn{2}{|c|}{$\begin{array}{ll}16 & 19.8\end{array}$} & $\mathrm{CO}_{2}$ & 4.75 & 0.2 & - & \multirow[t]{3}{*}{+} & + & & & - \\
\hline & & 2122.8 & S. W. & 8.19 & 0.2 & - & & + & - & & - \\
\hline & & $24 \quad 21.5$ & S. W. & 8.19 & 0.1 & - & & - & + & - & - \\
\hline & & $27 \quad 20.8$ & S. W. & 8.19 & 0.2 & - & \multirow[t]{2}{*}{-} & + & + & - & - \\
\hline & Apr. & $18 \quad 18.0$ & $\mathrm{HCl}$ & 3.04 & 0.2 & - & & - & + & - & - \\
\hline \multirow{6}{*}{ 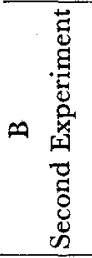 } & Date & 'Temp. & Solute & $\mathrm{pH}$ & Vol. & $\begin{array}{c}\mathrm{O} 1 \\
(17)\end{array}$ & $\begin{array}{c}\mathrm{O} 2 \\
(22)\end{array}$ & $\begin{array}{r}\text { O3 } \\
(18)\end{array}$ & $\begin{array}{r}\mathrm{O} 4 \\
(20)\end{array}$ & $\begin{array}{r}06 \\
(14)\end{array}$ & \\
\hline & \multirow[t]{5}{*}{ '75 Aug. } & 1227.5 & $\mathrm{CO}_{2}+\mathrm{NH}_{3}$ & 8.2 & 0.2 & + & - & - & + & - & \\
\hline & & $17 \quad 27.4$ & $\mathrm{CO}_{2}+\mathrm{NH}_{3}$ & 8.2 & 0.2 & - & - & - & - & - & \\
\hline & & 1927.3 & $\mathrm{CO}_{2}$ & 5.0 & 0.2 & + & + & - & - & - & \\
\hline & & $21 \quad 27.3$ & $\mathrm{CO}_{2}$ & 5.1 & 0.2 & + & - & - & - & - & \\
\hline & & $24 \quad 26.2$ & $\mathrm{NaOH}$ & 9.6 & 0.2 & - & - & - & - & - & \\
\hline \multirow{8}{*}{ 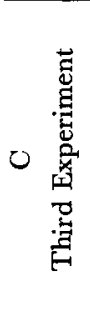 } & Date & Temp. & Solute & $\mathrm{pH}$ & Vol. & $\begin{array}{c}\mathrm{K} 2 \\
(73) \\
\end{array}$ & $\begin{array}{r}\text { K3 } \\
(68) \\
\end{array}$ & & & & \\
\hline & \multirow[t]{4}{*}{ '73 Sep. } & $15 \quad 21.9$ & $\mathrm{NaOH}$ & 11.1 & 0.02 & - & + & & & & \\
\hline & & 1921.4 & $\mathrm{NaCl}$ & 6.79 & 0.02 & - & - & & & & \\
\hline & & 2322.1 & $\mathrm{HCl}$ & 4.00 & 0.02 & - & - & & & & \\
\hline & & 2920.0 & $\mathrm{NaCl}$ & 6.79 & 0.05 & - & + & & & & \\
\hline & \multirow[t]{3}{*}{ Oct. } & $\begin{array}{ll}3 & 19.0\end{array}$ & $\mathrm{HCl}$ & 3.30 & 0.05 & - & - & & & & \\
\hline & & 1020.0 & $\mathrm{CO}_{2}$ & 3.10 & 0.05 & - & - & & & & \\
\hline & & $15 \quad 18.1$ & $\mathrm{HCl}$ & 3.80 & 0.1 & - & + & & & & \\
\hline
\end{tabular}


fluctuated in the range from 15 to $23^{\circ} \mathrm{C}$ through the experiment.

Results of experiments are shown in Table 2 (A), in which the positive effect of injected sea water is shown by $(+)$ and the negative effect by $(-)$. Colonies reacted to injection differently; some without any reaction, while others showed a wide variation from a slight expansion of the colony by $1-3 \mathrm{~cm}$ but without any reaction of polyps to a fully expansion of the colony with perfectly everted polyps
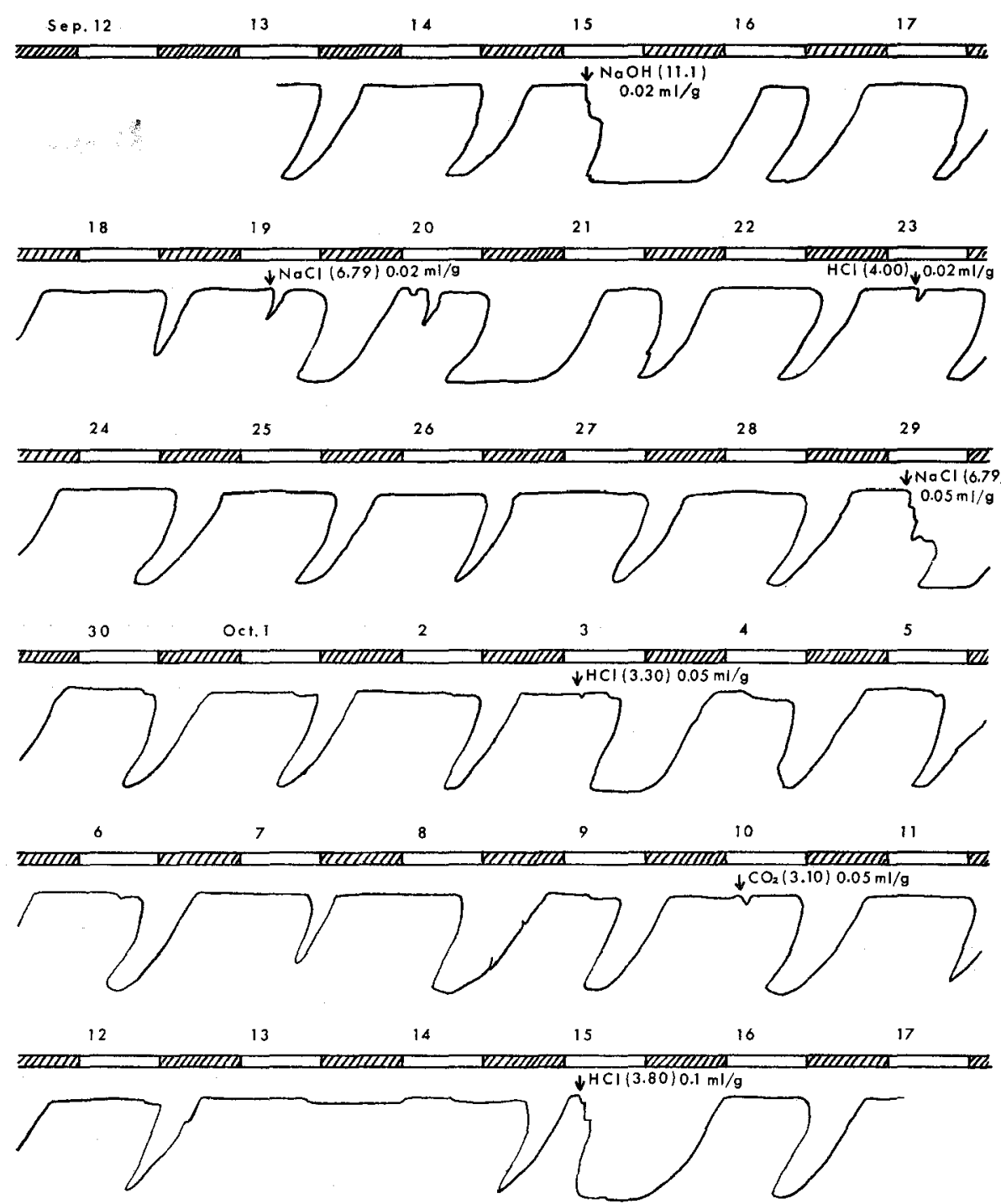

Fig. 2. Record of the expansion-contraction rhythm of the sea-pen (Colony K3) injected with saline solution (on September 19 and 29), alkalized by sodium hydroxide (on September 15), acidified by hydrochloric acid (on September 23, October 3 and 15) or by carbon dioxide (on October 10). 
through some intermediate states that are shown by expansion of the colony by several centimeters with swelling of polyps corresponding to the degree of colony expansion. As it is practically impossible to made any significant classification of such states, the effect of injection was judged quite arbitrary as positive when tested colonies exceeded half as long as in the normal expanded state, otherwise negative. The experiment with alkalized sea water, with $\mathrm{pH}$ from 9.20 to 10.70 , was done in the period from December 11 to January 23 at the water temperature $15-22^{\circ} \mathrm{C}$. Of 20 trials, two positive cases were met with. Therefore, the rate of positive effect was only $10 \%$, but anyhow the positive effect of alkalized sea water on expansion was seen clearly, because in expanding colonies there was observed the upward peristalsis as in natural expansion (Imafuku, 1975a) and the expansion by alkaline sea water attained nearly to the fully expanded state with numerous everted polyps.

Injection experiment with the sea water acidified by carbon dioxide acration to $\mathrm{pH} 4.42$ to 4.75 was carried out in five weeks from February 7 to March 16 at 18.0 $20.5^{\circ} \mathrm{C}$, the volume of injected sea water ranged from 0.1 to $0.3 \mathrm{~m} l$ per gram of animal. Of 19 trials, 7 gave the positive result and then the rate of positive effect was $37 \%$, clearly higher than in the case of alkalized sea water. The injection of sea water acidified by hydrochloric acid induced contracted animals to expand once in five trials.

The effect of natural sea water, with $\mathrm{pH}$ value 8.19 , was tested in a week from March 21 to 27 on the same colonies at $20.8-22.8^{\circ} \mathrm{C}$. Four of 15 trials were found positive, then the rate of positive effect was $27 \%$. In some colonies, the expansion was achieved as perfectly as in the natural state, as some colonies in the case of the injection of alkalized sea water.

From these results, it is apparent that each of alkalized, acidified and natural sea water can induce the contracted colony to expand and that there are differences in the sensitivity to injection; some colonies (colonies 5A, G1 and E2 in the experiments) never reacted to the injection, while others did to some extent, sometimes perfectly.

The Second Experiment (August 12 to 24, 1975)

Five colonies (O1, O2, O3, O4 and O6, weighing $14 \mathrm{~g}$ to $22 \mathrm{~g}$ ), kept together in a 100 liter aquarium and exposed to the natural daylight through the laboratory windows facing the north, were each injected on August 12 and 17 with sea water adjusted by carbon dioxide and liquid ammonia to maintain $\mathrm{pH}$ at 8.2, on August 19 and 21 with carbonated sea water, and on August 24 with sea water alkalized with sodium hydroxide.

The results are shown in Table 2 (B). The rate of positive effect of the injection of $\mathrm{pH}$-adjusted sea water was $20 \%$; namely two colonies expanded and their polyps everted, though the colonies never attained the fully expanded length and polyps were not expanded as perfectly as in the natural state, with tentacles somewhat contracted. At the injection of carbonated sea water, 2 colonies were induced to expansion on August 19 but only one reacted perfectly, some others only expanded the colony outside the sand bed by $1-5 \mathrm{~cm}$ on August 21 . No colonies reacted to 
the injection of alkaline sea water on August 24.

The Third Experiment (September 15 to October 15, 1973)

Two colonies $\mathrm{K} 2$ (73 $\mathrm{g}$ in wet weight) and K3 (68 g) kept in glass cylinders respectively and exposed to the artificial illumination of $12-\mathrm{h}$ hight and $12-\mathrm{h}$ dim light as in the first experiment, were injected with a $0.54 \mathrm{M}$ solution of sodium chloride isotonic to sea water, alkalized with sodium hydroxide or acidified with carbon dioxide or hydrochloric acid.

The results are shown in Table $2(\mathrm{C})$. The colony K2 never reacted significantly to any treatments, but only slight lengthening of the colony. Reactions of the colony K3 to respective treatments are illustrated in detail in Fig. 2. On September $15,0.02 \mathrm{~m} l$ of alkalized saline solution per gram of the tested colony was injected and this induced a prominent expansion as large as in the natural expansion and lasting longer than in usual rhythm. On September 19, isotonic saline solution was injected, but this caused only a little bit of expansion. However, such a small expansion was repeated without any treatment on the next day, September 20. This is a very interesting phenomenon that reminds us to what was quoted by Brown (1970) from the Bünning's work on the leaf movement of Phaseolus. Acid saline solution injected on September 23 did not induce any expansion. The second injection of saline solution on September 29 induced a clear expansion, the volume of saline solution injected being greater than in the first treatment on September 19. The second injection on October 3 of saline solution acidified with hydrochloric acid and the first treatment with carbonated saline solution on October 10 resulted in negative. Finally, the injection of $0.1 \mathrm{~m} l$ of saline solution containing hydrochloric acid per gram of tested colony induced a great expansion.

Results of all these experiments are summarized in Table 3. From this table,

Table 3. Results of injection experiments, summarized from Table 2. Number of positive injections/number of total injections is given, the rate of positive effect in percentage is given in parentheses.

\begin{tabular}{c|cccccc|c}
\hline & $\mathrm{HCl}$ & $\mathrm{CO}_{2}$ & $\mathrm{NaCl}$ & $\mathrm{CO}_{2}+\mathrm{NH}_{3}$ & $\mathrm{S.W}$. & $\mathrm{NaOH}$ & total \\
\cline { 2 - 8 } $\mathrm{m} l / \mathrm{g}$ & $3.0-4.0$ & $3.1-5.1$ & 6.8 & 8.2 & 8.2 & $9.2-11.1$ & \\
\hline 0.02 & $1 / 7$ & & $0 / 2$ & & & $1 / 2$ & $2 / 11(18)$ \\
0.05 & $0 / 2$ & $0 / 2$ & $1 / 2$ & & & & $1 / 6(17)$ \\
0.1 & $1 / 2$ & $3 / 7$ & & & $1 / 5$ & $2 / 20$ & $7 / 34(21)$ \\
0.2 & & $5 / 14$ & & $2 / 10$ & $3 / 10$ & $0 / 5$ & $10 / 39(26)$ \\
0.3 & & $2 / 8$ & & & & & $2 / 8(25)$ \\
\hline \multirow{2}{*}{ total } & $2 / 11$ & $10 / 31$ & $1 / 4$ & $2 / 10$ & $4 / 15$ & $3 / 27$ & $22 / 98$ \\
& $(18)$ & $(32)$ & $(25)$ & $(20)$ & $(27)$ & $(11)$ & $(22)$ \\
\hline
\end{tabular}

it may be concluded safely that acidified or alkalized sea water or saline solution induced the contracted colony to expand to some extent. A clear correlation between the volume of injected sea water and the rate of positive effect was not observed. Reasons for this are unknown at present, although it seems likely that the injection of a small amount of treated sea water is sufficient to induce an ex- 
pansion and that the differences in reaction to the same treatment as seen between on August 12 and 17 on colony $\mathrm{Ol}$ or $\mathrm{O} 4$ (Table 2B) are attributable to the process of injection itself; the needle point may reach inside the central canal of contracted colonies in some cases, but remain in the coenosarc in the others, though this can not be confirmed actually. Only stinging the colony with needle could not induce expansion, but when the needle inserted into the colony was roughly moved, the colony lengthened its body by a few centimeters above the sand bed without any reactions on polyps.

The fact that not only the carbonated sea water but also natural sea water, isotonic saline solution, alkalized sea water and so on could induce the contracted colony to expand is thought to be contradictory to the working hypothesis that the hydrogen ion concentraction plays an important role in the expansion-contraction rhythm of the sea-pen.

\section{Effect of Injection of Alkaline Sea Water to Expanded Colony:}

If the increase of the hydrogen ion concentration of the body fluid induces the contracted colony to expand and the decrease induces the expanded colony to contract, the injection of alkalized sea water to the expanded colony should cause a contraction.

This was examined on a colony (Colony L, weighing $22 \mathrm{~g}$ ) kept under the lightdark cycle and maintaining the regular active expansion in the dark phase. A 10 $\mathrm{m} l$ of sea water alkalized by sodium hydroxide $(\mathrm{pH} 9.8,0.45 \mathrm{~m} l / \mathrm{g}$ in contracted weight) was injected to the expanded colony in the dark phase on September 25 and 30. At injection, the top of the colony was held with fingers and the needle was inserted from the top of the colony. This caused many open polyps to close, with a beautiful greenish-blue fluorescence, and the colony itself to contract slightly for a while. In one to three hours, however, the colony recovered the usual expanded state, with many open polyps, that lasted till the end of respective dark phases (Fig 3). Therefore, slight contraction just after the injection might be induced by a

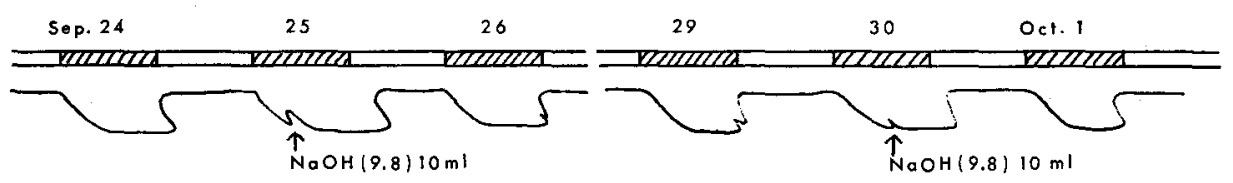

Fig. 3. Effect of injection of alkalized sea water on expansion. A $10 \mathrm{~m} l$ of sea water alkalized with sodium hydroxide $(\mathrm{pH} 8.9,0.45 \mathrm{~m} / \mathrm{g}$ ) was injected to the expanded colony (Colony $\mathrm{L}$, body weight $22 \mathrm{~g}$ ) kept in the light-dark cycle on September 25 and 30.

mechanical stimulation at injection rather than the direct effect of alkalized sea water injected, because it was confirmed that simple touch to the expanded colony caused a similar reaction (Fig. 5). In a repeated experiment, the $\mathrm{pH}$ of body fluid was measured just after the same injection and found to be 8.6, the value clearly higher than that of the normal body fluid of 7.3-7,8. 

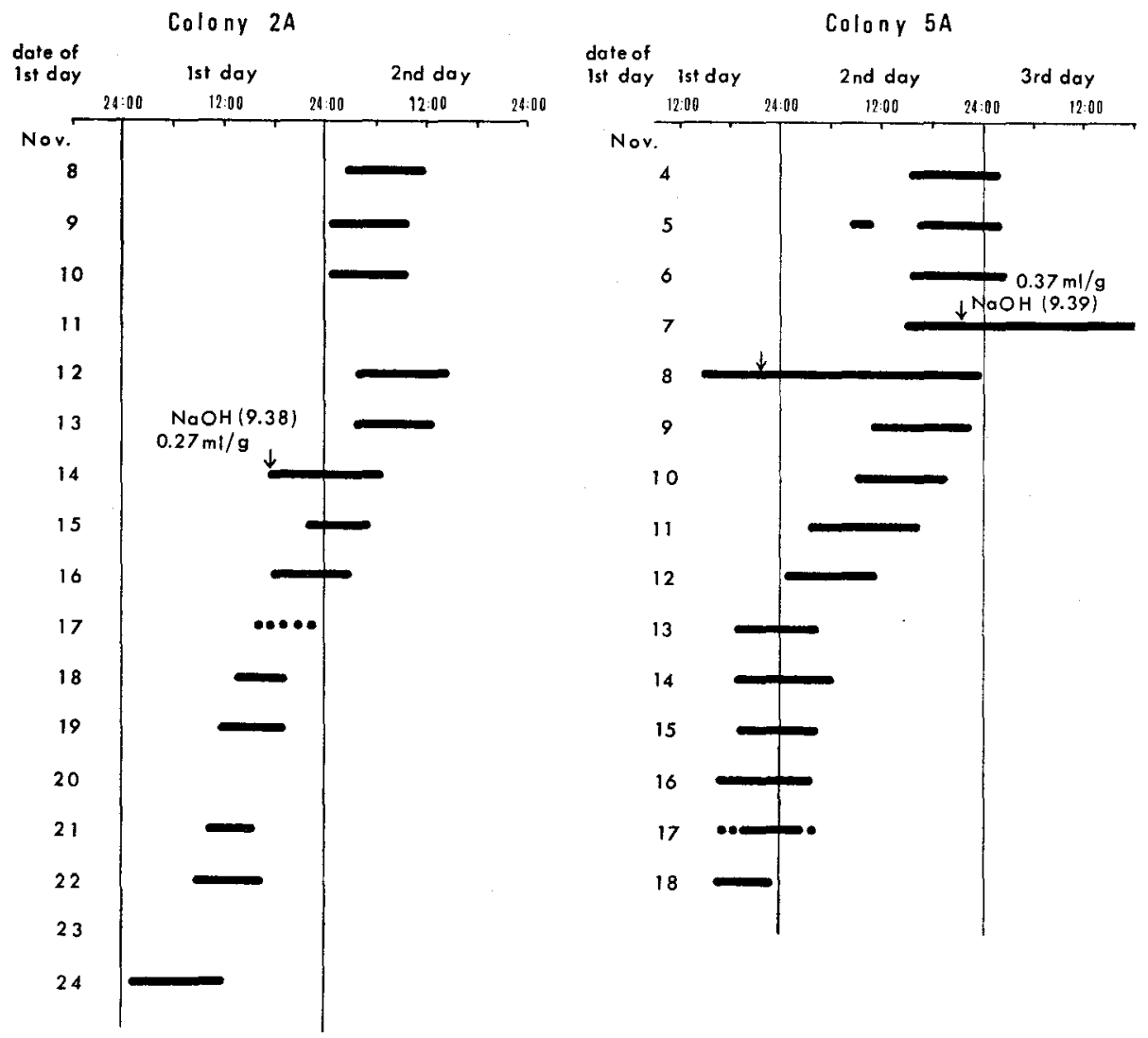

Fig. 4. Effect of injection of alkalized sea water on the expansion-contraction rhythm of the colony kept under the constant dim light. Colony 2A was injected with sea water alkalized with sodium hydroxide in a contracted phase on November 14, colony $5 \mathrm{~A}$ in an expanded phase on November 8 , colony 50 in a contracted phase on November 8 and 14. The active expanded phase is shown by a thick horizontal bar.

Thus, the injection of alkalized sea water could not induce the expanded colony to contract perfectly. This conclusion also throws doubt on the working hypothesis. If the working hypothesis were true, the injection of alkalized sea water would have to induce the expanded colony to contract according to a rise of $\mathrm{pH}$ of the body fluid.

Effect of the Injection of Alkalized Sea Water on the Rhythm of Colonies Kept under the Constant Condition:

It has been found already that a regular expansion-contraction rhythm is disturbed by the injection of acidified sea water, shifting the phase of rhythm, changing the period of rhythm, or bringing about an irregular rhythm. Then, it was examined if the injection of alkalized sea water brought about any changes in the rhythmic behavior of colonies kept under the constant dim light.

The colony 2A, showing a clear expansion-contraction rhythm, was injected 


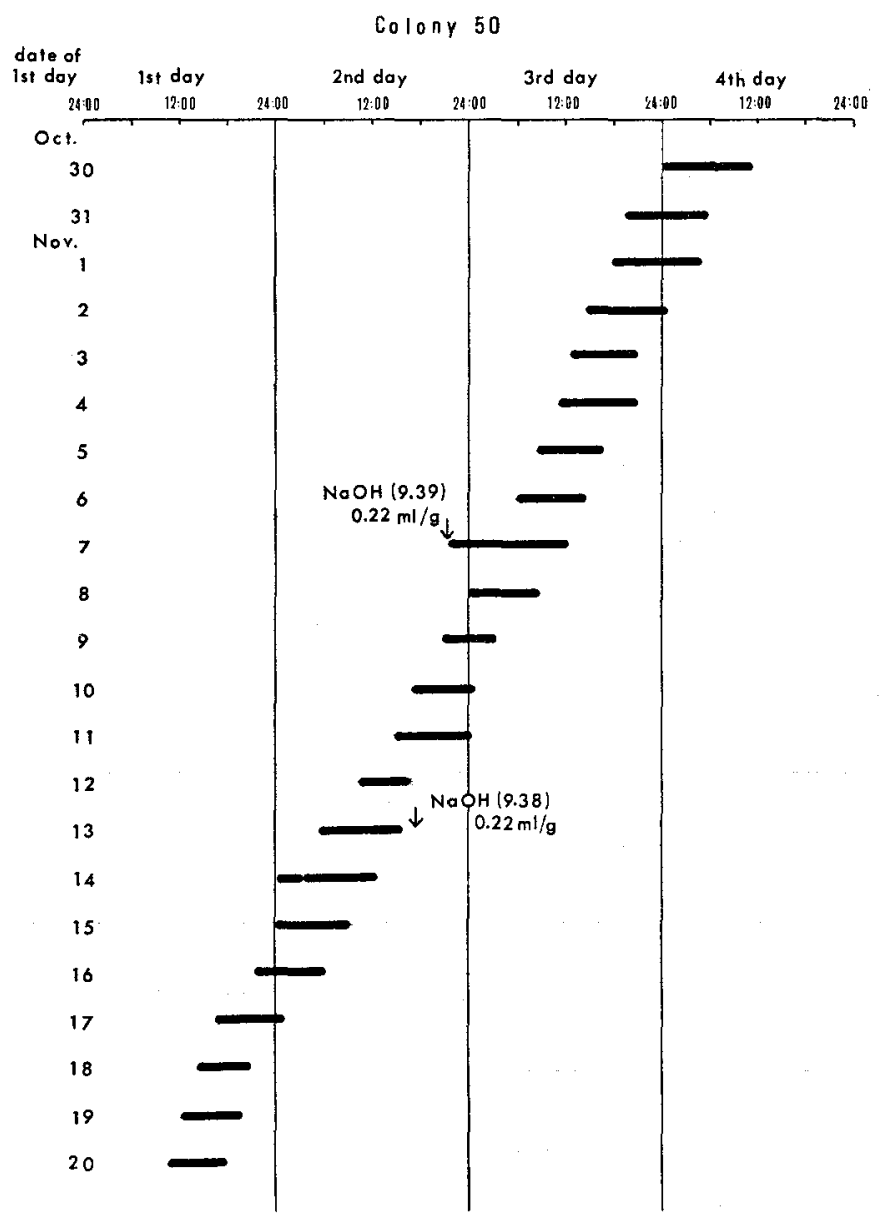

Fig. 4 (continued).

with alkalized sea water in the contracted phase on November 14 and this caused an expansion immediately (Fig. 4). After the injection, the active expanded phase moved to earlier hours of the day and the period of rhythm was slightly shortened to $21.7 \mathrm{hr}$. The colony $5 \mathrm{~A}$ was injected with alkalized sea water in the expanded phase on November 8 and this caused a prominent prolongation of that state that ceased on the next day nearly at the closing time of the expanded phase, accustomed in the regular rhythm. The third colony, no. 50, which has been showing the rhythm persistently for a long time, was injected with alkalized sea water two times on November 8 and November 14 respectively; the former injection induced the contracted colony to expand and brought about some prolongation of expanded state, while the latter was ineffective and the colony remained contracted.

From the behaviors shown in three colonies by the treatment with alkalized sea water, it was noted that the injection of alkalized sea water also might affect a regular rhythm by changing the period or phase of rhythm in some colonies, but relatively 
ineffective in some others. Here again, colonies seem to react differently to the injection. Furthermore, the difference of the effect of injection may be attributed to the difference in time of injection. Therefore, further examinations should be necessary to clarify whether the effect of injection would be dependent on the time of injection or not.

Effect of Mechanical Stimulation on the Rhythmic Behavior:

As described already, only a touch by fingers at injection caused a slight contraction in a colony. Then, to see the effect of pure mechanical stimulation on the rhythmic behavior, a colony kept under the constant condition of dim light and at the constant temperature of $28-29^{\circ} \mathrm{C}$ was experimented with in the days from July 23 to August 12 (Fig. 5).

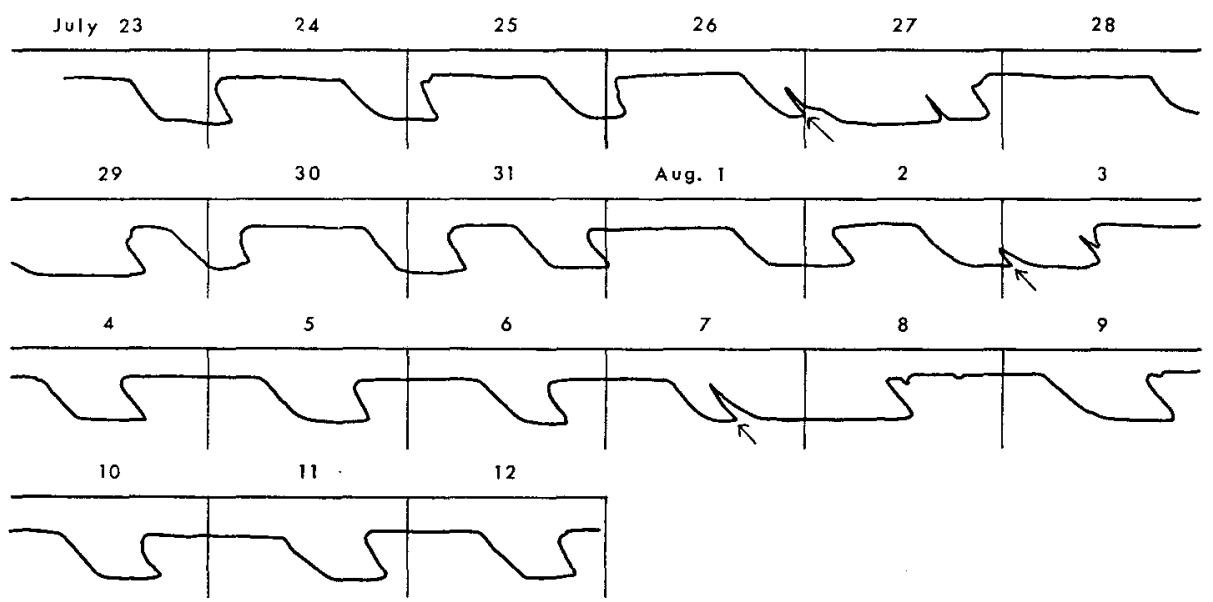

Fig. 5. Effect of mechanical stimulation on the expansion-contraction rhythm. The colony (Colony $\mathrm{N}$, body weight $27 \mathrm{~g}$ ) kept under the constant dim light was stimulated by finger touch on July 26 , August 2 and 7 as shown by arrows.

The colony (Colony N, weighing $27 \mathrm{~g}$ ) which had been showing a regular expansion-contraction rhythm was stimulated at night on July 26 by finger touch to the colony surface from the top to base of the rachis and then by pressing the colony strongly. This caused fluorescence, closing of polyps in a short time and shortening of the colony itself, that went on just similarly as in the usual contraction. But, the colony never contracted into the sand as usual. The colony contracted by stimulation began to recover the expanded state slowly and returned to the original fully expanded state in about 5 hours. The recovered expanded state was maintained for a long time till a perfectly contracted state appeared on the following day. The regular expansion-contraction rhythm with the active expanded phase at midnight was somewhat disturbed by this stimulation, but no phase-shifting was definable as the active expanded phase seemed unchanged as a whole.

The second stimulation was given to the same colony on August 2. This time, 
the stimulation was not so strong as in the first experiment; only light touch was given from the top to base of the rachis, but strong pressing was not applied to the colony. This stimulation caused fluorescence and closing of open polyps as in the first experiment, but shortening of the colony was not so strong as in the first treatment and the contracted colony recovered in 3 hours the usual expanded state that was followed 8 hours after by a usual contraction. This time, the active expanded phase of the colony was shifted to the daytime.

The third stimulation was given to the expanded colony on August 7 in a way to pinch the subapical portion of the colony with thumb and forefinger three times in a few seconds. Fluorescence was transmitted from the stimulated part to all rachidal area and all polyps were retracted into the coenosarc in a short time. Even this slight press made the colony contract largely, but the colony recovered in about 3 hours the usual expanded state which lasted to next noon. The active expanded phase was maintained in the daytime.

Throughout the three experiments, it could be concluded that the active expanded phase might be shifted by mechanical stimulations from midnight to the daytime as seen clearly in the case of the second stimulation, and therefore, the expansion-contraction rhythm of the sea-pen was regarded to be relatively unstable to mechanical stimulations.

\section{Discussion}

The present study was made to clarify the physiological mechanism of the expansion-contraction rhythm of the sea-pen, Cavernularia obesa, and focussed especially on examination of the working hypothesis that the increase of the hydrogen ion concentration of the body fluid, due to accumulation of metabolites in the contracted state, induces the expanded state of the colony, that allows the excretion of accumulated hydrogen ions, read by $\mathrm{pH}$ rise in the body fluid, and is followed by the contracted state.

As, already, the temperature coefficient of the metabolic rate had been estimated to be 2.53 and the period of rhythm had been confirmed to be temperature-compensated ${ }^{3)}$, both from 20 to $30^{\circ} \mathrm{C}$ (Imafuku, 1973), the $\mathrm{pH}$ of the body fluid was measured at different temperatures. The $\mathrm{pH}$ of the body fluid in the expanding state was 7.30 at $26^{\circ} \mathrm{C}$ and 7.44 at $15^{\circ} \mathrm{C}$ (Table 1). As a trial, the temperature-coefficient of hydrogen ion production was estimated. If it is supposed that the contracted period is the same in the two temperature ranges, hydrogen ions are produced at a constant rate during the period and then the hydrogen ion concentration at the beginning of expansion is correlated linearly with the hydrogen ion production, the temperature coefficient of the hydrogen ion production can be estimated to be

3) After suggestion by Prof. Chiba of Yamaguchi University, the term "temperature-compensated" was adopted instead of "temperature-independent", because the period of expansion-contraction rhythm of the sea-pen was not utterly insensitive to temperature changes (Imafuku, 1973). 
1.34 from the $\mathrm{pH}$ measurements at 26 and $15^{\circ} \mathrm{C}$. In other words, if it is supposed that the metabolic rate calculated from the oxygen-consumption is directly reflected on the hydrogen ion concentration of the body fluid, the $\mathrm{pH}$ difference between the two temperature ranges is calculated to be 0.44 and then the $\mathrm{pH}$ of the body fluid at $15^{\circ} \mathrm{C}$ will be calculated to be 7.74 on the basis of the actually measured $\mathrm{pH}$ value, 7.30 at $26^{\circ} \mathrm{C}$. As the actually measured $\mathrm{pH}$ values differ from this, it could be concluded that the metabolic rate is not directly reflected in the hydrogen ion concentration of the body fluid. Further, this does not always stand against the working hypothesis. The result of $\mathrm{pH}$ measurements may be explained by postulating that the sensitivity of muscle and nerve to the hydrogen ion concentration of the body fluid is also affected compensatingly by temperature, that is, the muscle and nerve may react to lower $\mathrm{pH}$ at higher temperatures but to higher $\mathrm{pH}$ at lower temperatures. If this is true, the results of $\mathrm{pH}$ measurement at different temperatures do not always stand against the working hypothesis.

The $\mathrm{pH}$ of the body fluid in the expanding stage was 7.3-7.4 not only in the regular rhythm but also after skipping an expansion (Fig. 1). Thus, it is suspected that metabolism might be somewhat depressed at the time of skipping an expansion or the $\mathrm{pH}$ of the body fluid might not be changed probably by the buffer action of the body fluid beyond a certain level even if the metabolism proceeds steadily when an expansion is omitted.

At any rate, the results of $\mathrm{pH}$ measurements may be explained with regard to the working hypothesis. However, the results of injection experiments seems to throw doubt on the working hypothesis. The injection of alkalized sea water or even of natural sea water caused contracted colonies to expand, though the effect of injection was not always identical among substances injected (Tables 2 and 3, Fig. 2). Some abnormal effect of injection was observed also by Mori (personal communication); the state of colony expanded by the injection of liquid ammonia, acetic acid or lactic acid showed some abnormal features, but that by the injection of carbonated sea water was quite natural. Though the effect of injection of various substances was not always quite similar, it could be concluded from the experiments that the expansion can not be attributed limitedly to the increase of hydrogen ion concentration, rather it may be due to the infusion of foreign matters into the colony. This is supported also by results of the other experiments, in which the injection of alkalized sea water to the expanded colony induced no contraction (Fig. 3) but resulted in a prolongation of the expanded state (Fig. 4, colony $5 \mathrm{~A}$ ), by which the injected substance might be gradually excreted. The working hypothesis is, therefore, seemingly unacceptable.

A modification of the working hypothesis may be possible as seen, for example, in next idea that the accumulation of metabolites, but not always the increase of hydrogen ion concentration, causes an expansion and the excretion of accumulated metabolites a contraction. However, this idea should be put aside as far as the phenomenon of skipping an active expanded phase in a regular expansion-contraction rhythm is noted, because the phenomenon can not be explained sufficiently by the 
idea. Generally, the metabolic rate is more or less affected by temperature and probably by other environmental factors, and such an effect of environmental factors may cause naturally some slight fluctuation in the period of rhythm, though the period cannot be changed suddenly from 24 hours to just 48 hours, as seen repeatedly in the cases of omitting an expansion (Figs. 1 and 4). Concerning the omission of expansion, the following comment was put forward by Mori (personal communication) on the base of the observation in which the contracted colony sometimes everted some polyps located at the top of the body (Mori, 1944b): At the time of omission the sea-pen may change the body fluid through probably everted polyps. The validity of this possibility should be confirmed by a continuous whole-day observation throughout the time of omission to see whether the sea-pen truely everts the polyps, though it was not always the case according to the observation made by the present author who watched intermittently, but not continuously, the contracted colony at the time of omission of expansion.

Examples of other organisms, similar to the omission of an expansion in the seapen, were discussed in the previous paper (1973), refering the works on Oedogonium (Bühnemann, 1955), Paramecium (Imafuku, 1972), Gonyaulax (Hastings and Sweeney, 1958) and some mammals (Rawson ,1960). Another example is the locomotory activity of cockroaches, in which a cluster of activity was observed at intervals of about 24 hours in the constant condition of medium temperature, but every other cluster was suppressed under the condition of low temperature, and this resulted in the appearance of a 48 hour rhythm (Bünning, 1959). These examples are common in the following aspect that there cannot be found any fixed correlation between the period and amplitude of rhythm, and this might be a strong basis to postulate a timekeeping mechanism independent of rhythmic phenomena.

Furthermore, it is expected that circadian rhythms in various organisms are based on the same mechanism, because they have some common aspects. The expansion-contraction rhythm of the sea-pen, Cavernularia obesa, has the following aspects common to other organisms. It is entrained to a light-dark cycle (Mori, 1944a) as well as to a temperature cycle (Imafuku, unpublished data). It can be entrained to different periods of environmental cycle in a certain range, but the period will becomes circadian when the period of light-dark cycle out of the range is applied (Mori and Ondo, 1957). And, such a range is not always identical among different organisms (Imafuku, 1975b). The period of rhythm is temperaturecompensated (Imafuku, 1973) in a certain temperature range (Mori, 1960).

On the other hand, the expansion-contraction rhythm of the sea-pen has some specific features. One is that the rhythm was easily affected by injection of alkalized or acidified sea water. Acidified sea water clearly shifted the phase of the expansioncontraction rhythm (Imafuku, 1973) and alkalized sea water change the period (Fig. 4). Therefore the effect of acidified sea water may be different from that of alkalized one. Further, in the case of phase-shift by the injection of acidified sea water, a transient (temporarily changed period when a new phase is attained by a single stimulus given in a constant condition) seemed to be unobservable. How- 
ever, much more data should be necessary to discuss these phenomena in detail.

The results of the injection experiment with acidified or alkalized sea water contrast prominently with the leaf movement rhythm of Phaseolus, that was not affected by $\mathrm{pH}$ change in the range of 3.2 to 8.0 (Bünning, 1956). Generally circadian rhythms are stable to chemical treatments, except for a few substances that were listed up in the previous paper (Imafuku, 1973). And the concept of the "clock" might be partly derived from such stability to various chemical treatments. Because of the stability the clock might be thought to exert its function in "one-way" (Sweeney, 1969) direction from the clock to the observable rhythmic process without feedback from the rhythmic process to the clock. However, the timekeeping mechanism of the sea-pen might have a feedback pathway because the artificial expansion with the injection of acidified or alkalized sea water induced a phase-shift or a change in period.

Another specific feature is that the rhythm is also affected by mechanical stimulations (Fig. 5). The effect of mechanical stimulations such as agitation of sea water is reported already in the tidal rhythm of some shore crustacean (Palmer, 1974), but generally the circadian rhythms are known to be rather stable to mechanical stimulations, as seen in Gonyaulax (Hastings et al., 1958)

The final conclusion throughout the results of the experiments carried out so far and considerations given above is that the expansion-contraction rhythm of the sea-pen is controlled by a certain mechanism independent of the rhythm similarly as in other organisms, but the mechanism in the sea-pen is susceptible to influences from both the inside, such as changes in the body fluid components, and the outside such as mechanical stimulations as well as illumination or temperature.

\section{Acknowledgements}

The present author wishes to express his sincere gratitude to Prof. Masaru Kato of Kyoto University, under whose supervision this work has been carried on, to Prof. Syuiti Mori of the same university, who gave the author many valuable advices and important suggestions through the course of this work, and to the staff of the Seto Marine Biological Laboratory for affording the author every facility for the works at the laboratory, especially to Prof. Takasi Tokioka for his help to complete the manuscript and also to Mr. Hidetomo Tanase for his assistance in collecting the material.

\section{REFERENCES}

Brown, F. A. Jr. 1970. Hypothesis of environmental timing of the clock. In "The Biological Clock: Two Views" pp. 13-59. Academic Press: New York, London.

Bühnemann, F. 1955. Das endodiurnale System der Oedogoniumzelle. II. Der Einfluss von Stoffwechselgiften und anderen Wirkstoffen. Biol. Zbl., 74, 691-705.

Bünning, E. 1956. Versuche zur Beeinflussung der endogenen Tagesrhythmik durch chemische Faktoren. Z. Bot., 44, 515-529.

1959. Zur Analyse des Zeitsinns bei Periplaneta americana. Z. Naturforsch., 14b, 1-4. 
1973. "The Physiological Clock". Heidelberg Science Library.

Hastings, J. W. and Sweeney, B. M., 1958. A persistent diurnal rhythm of luminescence in Gonyaulax polyedra. Biol. Bull., 115, 440-458.

Imafuku, M. 1972. A circadian rhythm of mating-type change and cell division in Paramecium multimicronucleatum, syngen 2. Zool. Mag., 81, 154-157. (In Japanese with English abstract).

1973. On some physiological aspects in the daily rhythmic activity of the sea-pen, Cavernularia obesa Valenciennes. Publ. Seto Mar. Biol. Lab., 20 (Proc. Second Internat. Symp. Cnidaria), 431-454.

1975a. Peristalsis in the monopolypid stage of the sea-pen, Cavernularia obesa Valenciennes. ibid., 22, 195-216.

1975b. Adaptation of the circadian rhythm of mating-reactivity to abnormal light-dark cycles in Paramecium bursaria. J. interdiscipl. Cycle Res., 6, 141-151.

Mori, S. 1944a. Daily rhythmic activity of the sea-pen, Cavernularia obesa Valenciennes. III. Controlling of the activity by light (1). Zool. Mag., 56/4-6, 1-5. (In Japanese).

- 1944b. do. IV. Observations of the activity in winter. ibid., 56/4-6, 6-10. (In Japanese). 1945. do. VIII. Endogenous daily rhythmic activity. Kyodai Seiri Seitai, 19. (In Japanese).

-_ 1947. A concept on mechanisms of the endogenous daily rhythmic activity. Mem. Coll. Sci, Kyoto Univ., Ser. B, 19, 1-4.

1960. Influence of environmental and physiological factors on the daily rhythmic activity of a sea-pen. Cold Spring Harbor Symp. Quant. Biol., 25, 333-344.

Mori, S. and Ondo, Y. 1957. Daily rhythmic activity of the sea-pen, Cavernularia obesa Valenciennes. XV. Controlling of the activity by light (3). Publ. Seto Mar. Biol. Lab., 6, 79-98.

Palmer, J. D. 1974. "Biological Clocks in Marine Organisms". Wiley-Interscience: New York, London, Sydney, Tronto.

Rawson, K. S. 1960. Effects of tissue temperature on mammalian activity rhythms. Cold Spring Harbor Symp. Quant. Biol., 25, 105-113.

Sweeney, B. M. 1969. "Rhythmic Phenomena in Plants". Academic Press; London, New York. 